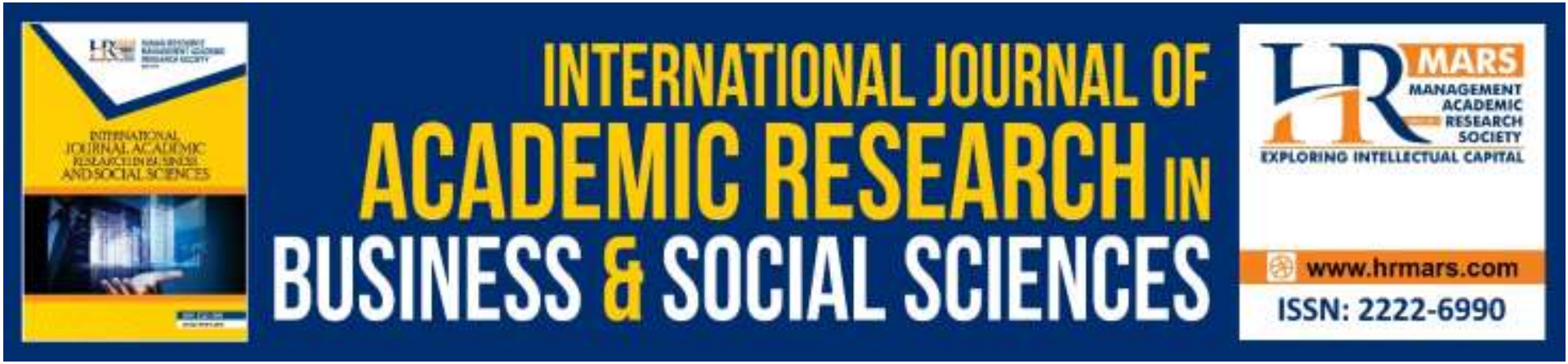

\title{
Counselling Cancer Patients: A Case Study of Perspectives of Professional Counsellors and Cancer Patients in Malaysia
}

\section{Siok Ping Voon \& Siaw Leng Chan}

To Link this Article: http://dx.doi.org/10.6007/IJARBSS/v11-i17/11398

DOI:10.6007/IJARBSS/v11-i17/11398

Received: 06 August 2021, Revised: 28 August 2021, Accepted: 26 September 2021

Published Online: 21 October 2021

In-Text Citation: (Voon \& Chan, 2021)

To Cite this Article: Voon, S. P., \& Chan, S. L. (2021). Counselling Cancer Patients: A Case Study of Perspectives of Professional Counsellors and Cancer Patients in Malaysia. International Journal of Academic Research in Business and Social Sciences, 11(17), 152-165.

\section{Copyright: (C) 2021 The Author(s)}

Published by Human Resource Management Academic Research Society (www.hrmars.com)

This article is published under the Creative Commons Attribution (CC BY 4.0) license. Anyone may reproduce, distribute, translate and create derivative works of this article (for both commercial and non-commercial purposes), subject to full attribution to the original publication and authors. The full terms of this license may be seen

at: http://creativecommons.org/licences/by/4.0/legalcode

Special Issue Title: Empowering Community and Beyond, iRandau, 2021, Pg. 152 - 165

Full Terms \& Conditions of access and use can be found at http://hrmars.com/index.php/pages/detail/publication-ethics 


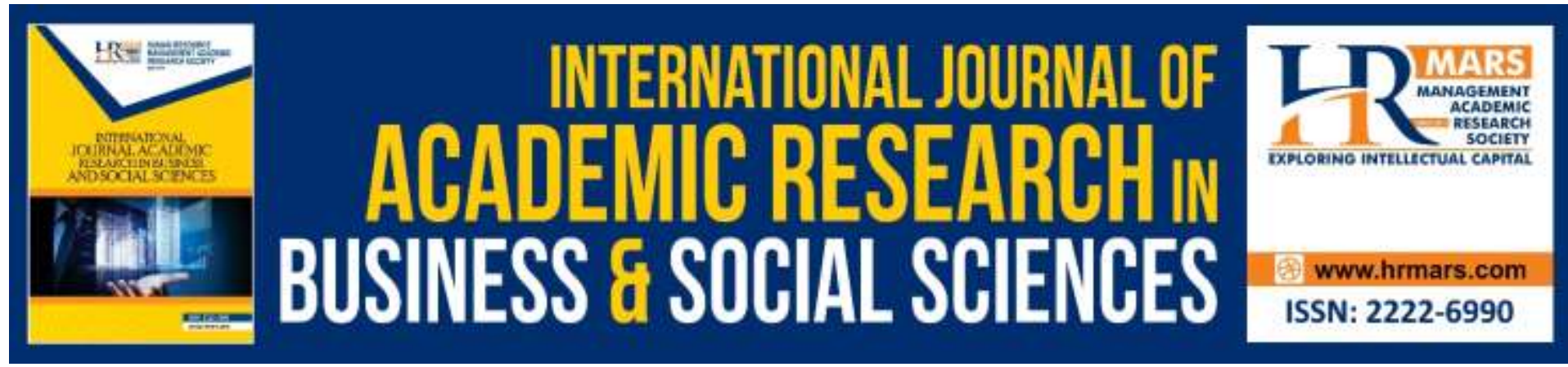

\title{
Counselling Cancer Patients: A Case Study of Perspectives of Professional Counsellors and Cancer Patients in Malaysia
}

\author{
Siok Ping Voon ${ }^{1} \&$ Siaw Leng Chan ${ }^{2}$ \\ ${ }^{1}$ Faculty of Cognitive Sciences \& Human Development, Universiti Malaysia Sarawak, \\ ${ }^{2}$ Department of Social Sciences and Management, Universiti Putra Malaysia Kampus \\ Bintulu Sarawak \\ Email: chansiawleng@upm.edu.my
}

\begin{abstract}
Globally, cancer is renowned as the top leading cause of death. Given the severity of this illness, cancer patients often experience different problems ranging from psychological adjustment and physiological changes to a financial burden. Counselling cancer patients is one treatment option provided to provide support and constructive coping of uncertain outcomes. The present case study aimed to explore the counsellors' perspectives in counselling with cancer patients and cancer patients' views in counselling. This research study utilised a qualitative case study design to investigate the patients' and counsellors' perspectives in-depth. A professional counsellor who has experience in counselling cancer patients and cancer patients was recruited to learn about central importance issues in this study. Six themes have emerged from the research: (1) opinion about cancer, (2) opinion regarding counselling with cancer patients in Malaysia, (3) problems and concerns surround cancer patients, (4) difficulties and challenges working with cancer patients, (5) needs of the terminally ill, and (6) strategies and recommendations in counselling cancer patients. The finding provides professional counsellors with some indications in working together with cancer patients and terminally ill patients, which can be a complex and challenging process.

Keywords: Cancer Patient, Case Study, Counselling Cancer Patient, Malaysia, Perspective
\end{abstract}

\section{Introduction}

A terminal illness is a medical term used to describe a progressively worsening disease that typically results in death. In today's world, cancer is swiftly steered to the top of the list of causes of death. Cancer is one of the most referred to terminally illnesses, and the client is referred to as a terminally ill patient. According to the World Health Organization (2021), cancer is a leading cause of death worldwide, accounting for 9.6 million deaths in 2018. Globally, deaths from cancer are estimated to continue rising, with an estimated 10 million deaths in 2020 and cancer is expected to fold up in Malaysia by 2040 after heart disease (Schliemann et al., 2020). There is no doubt that terminally ill patients are liable to death within a short period, and there is no adequate treatment that can cure the terminal illness. 
According to the World Health Organization (2021), cancer diagnosis and treatment are complemented by psychological support.

Cancer patient experiences different problems ranging from anxiety and depression (Chan, Hutagalung, \& Lau, 2017), abandonment, ineffective and burdensome treatments, loss of autonomy, fear of becoming a burden on others. With the transitions, a cancer person goes through multiple setbacks. There is a need to assist the cancer person and their family through this period of illness and ultimately accept death peacefully. Counselling comes to the fore as having an important role to play. Counselling can bring numerous benefits to a person with cancer (Wright, 2009). Essentially, counselling aims to support a person to develop healthy ways to understand and respond to emotional needs and concerns. Counsellors do not solve their problems, but they provide a safe environment where people with cancer can talk about their concerns. They offer a helpful, outside perspective (Cancer.Net, 2009).

Yet, the need for help for a cancer person is very individualistic (Laborde, 1998). Some people need professional service from the moment they realise they have cancer. Some make use of diagnosis as a catalyst to address specific issues and vital changes in their lives. Some manage to handle the crisis themselves with the support and help from family and friends. For many, it is like any other problematic situation, and they use whatever has usually worked in the past to fix the problem. They seek assistance when that does not work. People will exhaust their natural abilities and coping skills until they decide they cannot do it independently. Then they will seek professional help (Laborde, 1998).

When a person is diagnosed with cancer, they must face devastating news, surgery, or follow-up chemotherapy. Laborde (1998) said that diagnosis brings an immediate response to the devastation. Early support is needed for parents and family members who are initially very emotional and unsure how to cope with the illness. A counsellor's impact on a terminally ill client can be detrimental to the client's quality of life. Therefore, the counsellor needs to be aware of their place along the continuum of death awareness and anxiety to support the client's movement through phases and stages.

The main question of relevance was counsellors' perspectives in counselling with cancer patients in the Malaysian context. And what are the viewpoints of cancer patients in counselling in Malaysia? The current study aimed to explore counsellors' perspectives in counselling with cancer patients in the Malaysian context and explore cancer patients' views in counselling. Justification for the need to examine the attitudes of counsellors and clients in counselling demonstrated in the seemingly observed situation that counselling the terminally ill population can be complex and challenging.

\section{Method}

\section{Design}

This research study utilised a qualitative case study design to provide an in-depth investigation to explore the clients' and counsellors' perspectives in counselling with cancer patients in Malaysia. One-to-one semi-structured interviews with the counsellors and cancer patients were the primary data source for the current study. Interviews were one of the most compelling ways to understand the participants' point of view and uncover the meaning of their values, beliefs, and experiences (Creswell \& Poth, 2016). A semi-structured interview was advantageous as it provides a robust set of instructions for the interviewer and allows the interviewer to identify new ways of understanding the topic that may stray from the interview guide. 


\section{Participants}

Purposive sampling was utilised to recruit registered counsellors who have experience in counselling terminally ill clients, particularly cancer patients and clients or prospective clients with cancer, to learn about central importance issues in this study. A registered professional counsellor with experience in terminally ill clients and two adults with a terminal illness (cancer) was involved in the current study. The counsellor has extensive experience in counselling with diverse clients in the tertiary healthcare setting. The other two participants were 57 years old Chinese Buddhist married women diagnosed with Breast cancer, Stage One and 26 years old Chinese Christian married man who has been diagnosed with cancer, Hodgkin's Lymphoma, and Stage Four. In this study, participants were identified by the pseudonyms "Anne" (the counsellor), and "Amy" and "Albert" (the clients).

\section{Materials}

Interview protocols with a list of questions or topics that need to be covered were developed. The interview topics for the counsellor included personal and professional background, general opinion regarding counselling with cancer patients like counselling needs, attributes, and skills; work experiences including challenges in counselling with cancer patients and strategies in dealing with the experience in Malaysia. The counsellor also interviewed the diversity and multicultural issues in counselling clients with cancer, tips, and recommendations for counselling a cancer person.

\section{Data Collection}

The researcher arranged the interview date, time, and venue with participants who agreed to be involved in the current study before the interview session. A Letter to Participant and Consent Form was explained and given to the participants during the interview session. They were briefed about the research and were then asked to sign the consent form. Following the review and signing of the consent form, the interview session started. Each participant was interviewed once separately, and each interview session took approximately 45 minutes. Interviews were audio-taped, and field notes were made during the interviews. All interviews were transcribed in English.

\section{Data Analysis}

The output for analysis (transcriptions and field notes) from individual interviews was interpreted and coded to extract common themes, patterns, and differences among the experiences. The data obtained searched for the perspectives of clients and counsellors in counselling with cancer patients in Malaysia. The researcher utilised pseudonyms on all documents (demographic information and interview transcriptions) to keep the confidentiality and privacy of the procedures. After concluding the transcription, the researcher revealed several themes that arose during the interviews.

Data collected were analysed applying Morse's four stages of analysis steps (Morse, 1994) to obtain the core of the participants' lived experiences. This framework lets the researcher code all responses and organises them according to the appropriate categories of challenges the participants face. This approach allowed the researcher to code all answers and categorise them according to the pertinent aspects the participants meet. As commonly observed in qualitative case studies, the conclusions were not conclusive. Still, they were intended to add to the growing knowledge (Creswell \& Poth, 2016) based on the challenges 
faced by cancer patients and professional counsellors in counselling with cancer patients in Malaysia.

\section{Results}

Six themes have emerged from the data findings: (1) opinion about cancer, (2) opinion regarding counselling with cancer patients in Malaysia, (3) problems and concerns surround cancer patients, (4) difficulties and challenges working with cancer patients, (5) needs of the terminally ill, and (6) strategies and recommendations in counselling cancer patients.

\section{Theme One: Opinion about Cancer}

Different people had different views on cancer. Also, the reactions to a cancer diagnosis were as diverse as the individuals. One common thing people first think about cancer is that it is life-threatening and typically results in death. However, their perception of cancer can change due to their past experiences or understandings related to cancer.

'Cancer is a terminal illness, it brings death, and people can do nothing about it. I feel afraid when knowing nothing about cancer but now feel better. I accept and go with the flow.' (Amy)

'For me, at first, cancer is fatal. Yet, I realise that cancer can be treated now and not necessarily bring death after seeing my mother having breast cancer but being treated. Cancer is common nowadays. I believe that more pessimistic people are prone to have cancer. Positive thinking helps recovery from cancer.' (Albert)

Moreover, one typical response was for patients to become focused on the diagnosis and treatment details. They used the resources available and searched for information about the disease to better understand their diagnoses, leading them to arrange and decide which doctors to see, what procedures to have, and when to schedule surgery and chemotherapy that the patients may need.

Eventually, they become more aware of their feelings about the illness and its consequences. For instance, they think about death, how cancer will affect them, what they will do, what will happen to their children, spouse, and caregiver.

\section{Theme Two: Opinion regarding Counseling with Cancer Patients in Malaysia}

Both clients in the study reported that they did not seek counselling. They also noted that the need for counselling is very individualistic and serves different purposes for individuals. The following comments are illustrative for the issue:

'Indeed, counselling is helpful if people seek it. It helps. Counselling might be most beneficial for those who are in chronic condition, helpless, and stress. Different people have different opinions, depends on what condition they are facing. I was fine. Perhaps I was being diagnosed at the very early stage, and I "look through" it.' (Amy)

'Counseling helps those with a pessimistic mind or close-minded, but people should know what counselling should be. I think counselling should let people 
change their minds or attitude about cancer. It is crucial as it can make people feel better when they have different thinking about cancer.' (Albert)

When counselling cancer patients in Malaysia, the counsellor reported two types of patients: in-patient and out-patient. 'In-patients' were admitted to the hospital and referred by the doctors counselling in the hospital. Being referred to as patients who could not handle their diagnosis with cancer and cope with the crisis. 'Out-patients' referred to the walk-in patients in which their acceptance levels were shallow.

When asked about how diversity and multicultural issues can influence the work as a counsellor in counselling clients with cancer, the counsellor commented:

'One step in the counselling session can be considered as multicultural counselling already. When the client is diagnosed with cancer, we need to be aware of their disease acceptance. For terminally ill patients, their acknowledgement is usually shallow if they come and walk-in for counselling. If the counsellors don't know what cancer is or have no experience dealing with a terminally ill client, it's tough to put themselves in clients' shoes.' (Anne)

Counselling with cancer patients can be with basic counselling skills, but specific conditions were necessary to adequately practice counselling with cancer clients in Malaysia. Counsellors need to know about terminal illness, competency and know their values.

'Counsellors need to be well-educated. Not everybody can do counselling with a terminally ill person, and counsellors need to know their condition. Counsellors need to have the education and learning on how to deal with the client. For example, when some clients come in with exhausted faces and do not want to talk or share, inexperienced counsellors might still ask them to share or talk.' (Anne)

'Counsellors need to be competent in dealing with this kind of client. Counsellors need to practice and get hands-on experience to deal with terminally ill people in the field. Also, we need to be aware of our values. Clients project a lot in the session, and their acceptance level is deficient. It took about four to five sessions before they could accept the reality. It takes time.' (Anne)

Alongside, counsellors are encouraged to address their counselling needs as preparation before attending to cancer patients.

'Counselors need to be prepared in terms of feeling and the acceptance level of the client's culture." Counsellors need to know their values. Counsellors need to prepare themselves very well before entering one session, mentally or emotionally.' (Anne)

The following comments revealed other attributes or characteristics of counsellors of utmost importance in counselling cancer patients.

'Acceptance. Counsellors need to accept the client as who they are or what condition they are in at that point in their lives. Patients always think that we 
have biases or negative feelings towards them and look down on them. Sometimes clients cry in the session.' (Anne)

'Counselors go with clients' emotional journey, and the counsellor themself will cry together with the client. It is okay to cry. Yet, as competent counsellors, we need to know when to hold back and stop crying earlier than the client. Also, the counsellor should be happy-go-lucky. Happiness is crucial as it gives out positive energy to the client. Clients are often surrounded by negative feelings of sadness from people around them, so we need to bring them happiness. Nothing can do with a terminal illness but share acceptance and forgiveness with the client.' (Anne)

\section{Theme Three: Problems and Concerns Surround Cancer Patients}

The diagnosis of cancer presented enormous challenges both for patients and those close to them. Clients expressed that the process of searching and getting services was full of challenges and roadblocks. The initial attempt to obtain information, resources and treatment was a time-consuming and complicated process.

'But the issue at first was, we do not know what doctor to see. Should we go for traditional Chinese or Western medicine?' (Amy)

'My family and I searched for information on both traditional Chinese and Western medicine. We seek bits of advice from specialists in Western medicine as well as traditional Chinese medicine doctors.' (Albert)

Clients also expressed their initial difficulties in the journey of fighting cancer. 'At first, I was coughing. I went to the hospital. After I went through an X-ray, biopsy, and all that, the doctor couldn't answer, and I am still unsure about my condition. I was depressed. That made me went to see another doctor for a second opinion.' (Amy)

'It took a very long time ( 2 to 3 months) to be diagnosed in Malaysia due to the long duration before the next appointment. When I finally went back to the hospital for follow up, I was advised by the doctor to get treatment as soon as possible. At that time, I was still in the denial stage.' (Albert)

Success in obtaining needed information and services brought considerable relief for the patients, as expressed by the participants.

'The information showed no real-life example or successful case of a cancer person treated by traditional Chinese medicine, but there are successful examples in Western medicine. For instance, cancer persons prolong their life after chemotherapy. So, my children made the decision, and we went for Western medicine. '(Amy)

'It is a great relief for being diagnosed with cancer as I finally get the answer and know what happened to me.' (Albert) 
Furthermore, clients stated what they were concerned about the most after being diagnosed with cancer.

'I worry about my family as I know that they are worried about me.' (Amy)

'Also, I feel very guilty about my wife as she needs to bear all these things just after marriage. Sometimes I think that it might be better if we didn't get married yet.' (Albert)

Death appeared to be the biggest problem the cancer person faced. The terminally ill patients and their family members are affected psychologically and emotionally by the fear of death. Cancer seems to them the doorway to premature death.

'There is a possibility of recurrence of the illness or relapse.' (Albert)

However, no client reported financial barriers in fighting cancer in Malaysia in the current research, as expressed by one of the clients,

'For me, financial is not a big problem. The fees of doing treatment in government hospitals are affordable.' (Amy)

\section{Theme Four: Difficulties and Challenges Working with Cancer Patients}

When cancer is diagnosed in any family member, a state of crisis characteristically emerges for the entire family. The counselling involved not only the cancer patients but the whole family

'Besides counselling with the client, I had individual counselling with each client's family members (his wife, two sons, and two daughters). Then we proceeded to family counselling as a group. Many family issues come out after that. The eldest son blamed the father for leaving them since he was young and came back for ten years, and then he was going to like gone forever. The wife couldn't accept the reality as she couldn't afford to lose her husband again.' (Anne)

The counsellor indicated that competency appeared to be one of the challenges in working with cancer clients and dealing with the experience. Moreover, the counsellor claimed that countertransference and transference was the most challenging issue.

'It was time when the second son of the client questioned my profession and my competency. The son was older than me, ten years, and he claimed that I was still young and knew nothing about it and for what purpose I could conduct the session. Yet, eventually, he accepted after seeing how I work.' (Anne)

'Counsellors need to be confident. We cannot avoid having this type of client who challenges us, questions our competence level by saying, "How well you can deal with my case?" "What do you know about me?" Counsellors need to trust that they can do it, and actions speak louder than words. If you really 
cannot deal with it, ask the client if they can refer them to other counsellors.' (Anne)

The counsellor also explained the multicultural issues, for example, the impact of religion, spirituality, and cultural considerations in counselling with a cancer patient.

'It's about death and dying. The patient's spirituality is high. No matter what religion they are, it becomes the same when it comes to spirituality. For the patient, it's time to get close to another world, with God, and to prepare themselves very well.' (Anne)

The counsellor pointed out the challenges of diversity in counselling by sharing her experience.

'In the session, the indigenous client talked about God, which I didn't know at all. I didn't understand the client. I was having a tough time with the client. In addition, the language barrier was one of the challenges. Our values were also different. The client asked me to sit very far from her as the client felt shame with her smell. I reassured the client, saying that I was okay with it. But if the client feels uncomfortable with the counsellor, I will distance a little bit from the client. No clients don't like if counsellor being too far away as that indicates shame.' (Anne)

\section{Theme Five: Needs of the Terminally III}

When faced with the news that a family member has been diagnosed with cancer, many people worry about what they should say and do. They want to help but often don't because they are afraid to say or do something that will further upset the loved one. However, many of their needs can easily be met by family members and friends. One of the needs was like a social need as they want to be treated like usual and hope for social involvement like before.

'Don't treat a cancer person as a patient as it might remind us of our illness or unfortunate thing. People should see cancer as a fever, and that makes life easier. Just treat us like ordinary people. Would you mind giving us the fundamental concern? One time should be enough and don't keep repeating, saying, or asking the same things.' (Albert)

'But I care how others think or look at me as a cancer patient (for example, some people try to avoid cancer person or get close to me).' (Amy)

In addition, social support from friends and family appeared to be the primary need of the cancer persons. Spiritual needs have played one of the vital roles.

'I am a Buddhist. For me, religion provides mental support, and I found inner peace. I believe in God even don't know if it's helpful. Spirituality comes naturally.' (Amy)

'For me, prayer is helpful. For example, I felt like vomiting after chemotherapy, and then I prayed. I felt comfortable and found that prayer helped, even though it's not very obvious. Religion is like mental support, and I believe in God.' (Albert) 
The current study demonstrated that it was important for cancer patients to have positive thinking, acceptance, forgiveness, and gratefulness to help them better cope with the illness. Also, their experiences gave them a great life lesson which was helpful for others in life as well.

'Accept or face reality, be very open-minded, and has positive thinking. If you believe "It's not a big deal," then every problem is not a problem. Live happily.' (Amy)

'The whole family became closer after I was diagnosed with cancer. I was blissful as all family members from the family of origin, nuclear family, or extended family love me and take care of me. I felt grateful to God, I viewed this challenge in life as a gift to me, and I was beloved because of cancer.' (Amy)

'Health is important. People should have positive thinking. People nowadays (even before) always think that money is essential, but it's not when people are sick. Money couldn't get the health back.' (Albert)

\section{Theme Six: Strategies and Recommendations in Counseling Cancer Patients}

Counselling can help a cancer person in numerous ways. Choice of treatment options appeared to be an issue in counselling which counsellors need to be aware of. Hence, knowledge regarding the choice of treatment options is vital.

'Clients always say, "I don't like the chemotherapy," "I don't know how to survive already," and so on. The client will ask if we can decide for them. They will ask should they end their life or go for chemotherapy. Chemotherapy is very torturing, and they do not want to bear with it. Yet, counsellors need always to remember that they cannot make decisions for the client but let them see what they want.' (Anne)

To better serve cancer clients in the Malaysian context, the counsellor suggested the following:

'Counselors need to be alert. Observe the client's overt behaviour but do not express it out. Counsellors can have the curiosity but do not show it out. Instead, do it in another way, like asking some facilitative questions. Counsellors need to be aware of sensitive statements. Different clients have different touchy words.' (Anne)

Moreover, the counsellor recommended the need to be prepared to effectively counselling clients with cancer.

'Validate the client. Help them to go on living happily, accept the reality. Never put your values on them. Also, be aware that cancer or terminally ill clients do not look good physically. Some of them have smelly body odours and do not have a positive mind. If the client asked to help them with the wound, help them. Be ready to accept them.' (Anne)

'Go more to charity homes and see more of this kind of patient. Get to know your value know if they can deal with this kind of patient. If no, then refer to 
it. Do not judge the patient. They can sense it. The acceptance level should be very high as it involves not only the person but people around them.' (Anne)

\section{Discussion}

In working with cancer patients, counsellors need to be well-prepared in knowledge, skills, and awareness. Counsellors need to have special education on terminal illness to understand the client's condition better. Counsellors in dealing with cancer clients should show a high acceptance level. They need to be aware of their values in working with cancer clients. In addition, counsellors should involve in practical training or internship. They can voluntarily work in charity homes or hospitals to get more hands-on experience dealing with cancer patients. Besides, the characteristics or attributes of counsellors are essential.

Countertransference appeared to be the most challenging issue for counsellors. Counsellors need to be mindful of personal reactions in working with cancer persons. Death anxiety of the counsellors is triggered in working with clients with cancer. Counsellors need to be careful in the topic of death and effectively manage personal reactions and then facilitate the client's exploration of the meaning of their life or thoughts and feelings of death and the dying process (Wright, 2009). It is distressing for counsellors to see people who have not lived their lives to the fullest or are dying relatively young. Counsellors need to be aware that it is inappropriate to befriend a client and constantly maintain a therapeutic boundary.

Moreover, the study's findings suggested that dying persons have the exact physical, emotional, social, spiritual needs as everyone else. What they need most of all is to be cared about, not just cared for. Some of their needs can be supported by family and friends, and some cancer or terminally ill person's needs are particular. Individuals can only meet them with professional support.

Physical needs. One of the biggest concerns of a dying person is the control of acute and chronic physical pain. Those who place a high value on self-image may be concerned about hair loss, skin colour changes, dark circles around their eyes, and other physical appearance (Shriner, 2007). The client can no longer do the things they could do and may feel depressed or feel like a burden to others (Chan et al., 2017). Family members or professional caregivers can provide physical care that will help them to feel more comfortable. Counsellors can provide information on how the body changes, what changes to expect in the future and when to contact a physician (Daneker, 2006; Doka, 2007; Wright, 2009). Counsellors also need to be aware of their condition and be ready to accept them.

Emotional needs. Terminally ill persons are likely to express negative feelings, including anger, anxiety, sadness, fear, and guilt. Their emotions are real, and they need to be identified, acknowledged, and expressed. Hence, it is essential to take genuinely accept how and what they are feeling. However, many helpers are uncomfortable, and they wonder what they should say and do. The intense emotions experienced by dying persons are normal and can be alleviated by sensitive intervention (Daneker, 2006). Counsellors must address the anticipatory grief of the individual (Daneker, 2006; Doka, 2007).

Social needs. Individuals with terminal illnesses need social involvement as much as before the disease (Daneker, 2006). They may be concerned about their roles within the family, the workforce, to name a few (Shriner, 2007). Family members and friends of the person with cancer need to pay attention to getting enough support and space for themselves and getting their own needs met; otherwise, there is a danger of burning out. Therefore, counselling is available for anyone who has a cancer issue. Counsellors can 
facilitate the ability of friends and family to enable terminally ill individuals to maintain a social life in the face of physical limitations (Daneker, 2006; Wright, 2009).

Religious/Spiritual needs. Persons with terminal illness often bring up issues that are spiritual in nature (Shriner, 2007). Counsellors help clients find meaning in their lives and the disease, create a personal definition of an appropriate death, and help them transcend death, either through religion or an afterlife. The crucial spiritual need is transcendental in that people seek assurance that their life has had meaning and have contributed something of value (Daneker, 2006; Doka, 2007). The practice of religion and spirituality is associated with better physical and mental health.

\section{Implications for Counsellors}

Counselling with cancer patients is a very specialised and complicated matter. The preparation in personal and professional development is vital to serving a client with a terminal illness like cancer.

Higher institutions shall introduce death-related counselling issues or courses regarding counselling people with a terminal illness in Malaysia's counsellor education programs. The related program courses should be designed to equip the student counsellor with the necessary skills and techniques to assist terminally ill persons effectively. Their relations to cope with their present situation and smoothly transit into the terminal illness's various phases will bring. Moreover, cultural differences in handling death, the method of counselling the terminally ill, and counselling needs could be integrated into the curriculum to understand the terminally sick and ultimately enable students to be better counsellors. If there is no adequate curriculum in place, the student should attend workshops to increase their competency in this area.

Counselling with terminally ill like cancer patients requires not just counselling interventions but also knowledge of medicine. Counsellors need to have some medical background to understand better what should or should not be done for the clients. Sometimes counsellors cannot deal with clients' matters without the facts before them or lack principal medical facts about clients' cases. There are very particular types of skills involved, and counsellors who are in general practice at times will need to consult with or refer to a variety of professionals. Thus, counsellors need special education to better understand terminal illnesses like cancer, for example, the diagnosis.

Cognitive Behavioral Therapy (CBT) is a therapy that helps to recognise distorted beliefs, feelings, or behaviours that a client may have. This type of therapy can be extremely helpful in treating cancer clients if they have pain, distorted beliefs, or anxiety about their condition. Cancer patients being treated for pain revealed that the traditional CBT, which helps clients change their distorted thoughts, is equally effective with terminally ill clients suffering from anxiety or depression. Thus, counsellors can use CBT to work equally effectively with terminally ill clients who have anxiety and depression.

Furthermore, counselling with cancer patients involves the exploration of spirituality. The need exists for more counsellors training regarding spiritual or other multicultural issues in counselling the terminally ill. Counselling skills adequate for work with different populations may be too fragile and too shallow to endure the intensity and depth of focus in therapy with terminally ill people. Having a multicultural perspective is vital in counselling the terminally ill. Counsellors working with cancer patients need to be competent to effectively work through the last developmental life stage of patients. Therefore, other than knowledge and skills, counsellors need to be aware of their assumptions, values, beliefs, and 
biases to serve them better. A supportive atmosphere created in counselling is a microcosm that can have far-reaching effects on the terminally ill person's life.

Self-care for the counsellor is one essential aspect. Counsellors have no way of knowing which day would be their last session with the client. Working with cancer persons can be emotionally taxing, and counsellors feel grief when their clients die. Therefore, the counsellor must take care of themselves to prevent distancing themselves from their own emotions or their clients and prevent burnout. Some rituals might be helpful for the counsellor process grief, such as lighting the candle, keeping a memory journal, attending the funeral, or seeing a variety of clients to get balance in the counsellors' caseload.

Everyone lives along a continuum of death anxiety and death awareness, including counsellors and clients. As part of preparing to work with clients, counsellors should recognise their position along the continuum. Like racial identity issues in multicultural counsellor education, counsellors need to be aware of their own and their clients' death anxiety and death awareness levels. Individuals with a terminal illness, their families, and their counsellors inevitably experience a shift in where they are along this continuum. A counsellor should never assume anyone's cultural perspective, and they must allow the client to explore all their current thoughts and feelings about the death and dying process.

\section{Limitations of the Study}

The current study was subjected to few limitations. First, only one professional counsellor and two clients who were diagnosed with cancer were interviewed. Hence, the findings may not be able to generalise to the overall population. Essentially, the researcher shall use an ideal sample size to ascertain whether the results can be applied to various discrepancies in tangible lived experiences, disputes, and methods used by different people. Second, another important consideration was that all participants were limited to Chinese and other ethnic groups such as Malay and Indian were omitted. Third, the perspective of counselling with cancer patients and experiences of cancer patients might be affected by different ethnic groups, social, economic status, and community settings (e.g., rural vs urban). Last, the present study involved only adults with cancer. The perspective of counselling and the experiences of adults with cancer might be different from those with children with cancer. Therefore, an additional limitation of studies is the over-reliance on accessible informants and making inferences based on only a few concrete and vivid examples. Individuals who are involved in the study may be essentially different from other cancer patients.

\section{Conclusion}

Working with terminally ill individuals like cancer patients can be challenging and very rewarding for counsellors. Hence, it is essential to address the counsellors' and clients' issues and concerns based on their perspectives to better understand the counselling concept and process. The preparation of a counsellor personally and professionally is crucial as it enables counsellors to be better equipped and be competent in counselling clients with cancer, especially for new counsellors. Nevertheless, issues and concerns have been dealt with once does not mean that it is now resolved. The problems and circumstances surrounding the cancer persons are likely to be raised again, and there will always be more questions, needs, or concerns. Therefore, novice counsellors must have the skillset and knowledge to understand the issues and concerns surrounding a sick terminally client and care for them. 


\section{Acknowledgement}

We thank all the participants for their cooperation in this study.

\section{Reference}

Cancer.Net. (2009). The benefits of counseling. Retrieved April 28, 2021, from the World Wide Web:

http://www.cancer.net/patient/All+About+Cancer/Cancer.Net+Feature+Articles/Qu ality+of+Life/The+Benefits+of+Counseling

Chan S. L., Hutagalung, F. D., \& Lau P. L. (2017). Healing experiences of Malaysian young adults recovering from major depressive disorder: A preliminary study. In Lumban Gaol et al. (Eds), Trends and Issues in Interdisciplinary Behavior and Social Science (pp. 1-8). London: Taylor \& Francis Group.

Creswell, J. W., \& Poth C. N. (2016). Qualitative inquiry \& research design: Choosing among five approaches (2nd ed.). USA: Sage Publications.

Daneker, D. (2006). Counselors working with the Terminally III. Retrieved April 28, 2021, from the World Wide Web: http://counselingoutfitters.com/Daneker.htm

Doka, K. (2007). Counseling individuals with life-threatening illness. New York: Springer.

Laborde, K. L. (1998). Support systems: counseling for cancer. New Orleans Magazine, 33(2), 32-33.

Morse, J. M. (1994). Designing funded qualitative research. In N. K. Denzin \& Y. S. Lincoln (Eds.), Handbook of qualitative research (p. 220-235). Sage Publications, Inc

Shriner, J. A. (2007). Caring for the terminally ill. Retrieved April 28, 2021, from the World Wide Web: http://ohioline.osu.edu/hyg-fact/5000/pdf/Caring_Terminally_Ill.pdf

World Health Organization. (2021). Cancer. Retrieved April 3, 2021, from the World Wide Web: https://www.who.int/news-room/fact-sheets/detail/cancer

Wright, N. (2009). Counseling adults with terminal illness: what every counselor in training should know. Retrieved April 28, 2021, from the World Wide Web: http://www.winona.edu/counseloreducation/capstones/2009/fall/counseling_adult s_with_terminal_illness-what_every_counselor_should_know.pdf 